\title{
A new species of Seira Lubbock (Collembola, Entomobryidae), with a key to the species of Paraíba, Brazil
}

\author{
Bruno Cavalcante Bellini ${ }^{1} \&$ Douglas Zeppelini ${ }^{2,3}$
}

\begin{abstract}
${ }^{1}$ Departamento de Sistemática e Ecologia, Centro de Ciências Exatas e da Natureza, Universidade Federal da Paraíba - Campus I. 58059-900, João Pessoa-PB, Brazil. entobellini@yahoo.com.br

${ }^{2}$ Centro de Ciências Biológicas e Sociais Aplicadas, Universidade Estadual da Paraíba Campus V, João Pessoa-PB, Brazil.

${ }^{3}$ Associação Guajiru - Ciência - Educação - Meio Ambiente. Scientific Board.
\end{abstract}

\begin{abstract}
A new species of Seira Lubbock (Collembola, Entomobryidae), with a key to the species of Paraíba, Brazil. A new species of Entomobryidae of the genus Seira Lubbock, S. paraibensis sp. nov. is described and illustrated. The type locality of the species is the municipality of Areia, state of Paraíba, Brazil. The species was found inhabiting the Atlantic forest litter and top soil environment. S. paraibensis sp. nov. resembles S. pseudoannulata in many morphological features. This is the sixth species of the genus found and described in Paraiba so far. A key with the 11 species of Seira registered so far in Paraíba is provided. Also a list with all species of the genus from Brazil is presented.
\end{abstract}

KEYWORDS. Brazilian collembolan diversity; chaetotaxy patterns; Entomobryomorpha; list of species; Seirinae.

RESUMO. Uma nova espécie de Seira Lubbock (Collembola, Entomobryidae), com chave para as espécies da Paraíba, Brasil. Uma nova espécie de Entomobryidae do gênero Seira, S. paraibensis sp. nov. é descrita e ilustrada. A localidade tipo da espécie é o município de Areia, no Estado da Paraíba, Brasil. A espécie foi encontrada habitando o folhiço e solo superficial de um remanescente de Mata Atlântica. S. paraibensis sp nov. possui muitas similaridades em sua morfologia com S. pseudoannulata. Esta é a sexta espécie do gênero encontrada e descrita na Paraíba até o momento. Uma chave com as 11 espécies de Seira registradas até o momento na Paraíba é apresentada, juntamente com uma lista com todas as espécies do gênero encontradas no Brasil.

PALAVRAS-CHAVE. Diversidade brasileira de Collembola; Entomobryomorpha; lista de espécies; padrões de quetotaxia; Seirinae.

Entomobryidae is the most diverse family of Collembola (Bellinger et al. 1996-2008; Soto-Adames 2008). The species of this family usually have long appendages such as antennae, legs and furca, like other Entomobryomorpha (Bellinger et al. 1996-2008; Christiansen \& Bellinger 1998). Entomobryidae distinguishes itself from other families by the presence of multiciliated setae on body, an abdominal segment IV longer than III, crenulate dens and a small mucro with one or two well developed teeth (Zeppelini \& Bellini 2006; Soto-Adames et al. 2008).

Seira Lubbock is one of the most assorted genera in Entomobryidae with 178 described species so far (Bellini \& Zeppelini 2008). The genus is formed by epiedaphic species which are distributed predominantly in tropical areas (Bellinger et al. 1996-2008, Christiansen \& Bellinger 2000, Barra 2004). Many species of Seira were found in high temperature forested areas or even in open hot semi-arid regions, which points to the natural resistance of the group to the heat and water shortage. There are 48 species of Seira in the Americas, 20 of them occurring in Brazil (Mari Mutt \& Bellinger 1990, 1996; Mari Mutt et al. 1998-2008; Christiansen \& Bellinger 1998; Culik \& Zeppelini 2003; Bellini \& Zeppelini 2005, 2008; Zeppelini \& Bellini 2006).

The morphology of Seira is very similar to Entomobrya
Rondani and Lepidocyrtus Bourlet. Seira can be distinguished from other genera in Entomobryidae by the following features: the presence of yellowish or brownish rounded scales covering almost all the head body and at least the first segments of the appendages; the presence of seven or eight well developed lenses on each eye spot; and a falcate mucro (Jacquemart 1974; Mari Mutt 1986; Christiansen \& Bellinger 2000).

The newly described species of Seira was collected in forest litter and top soil of a transition vegetation called Brejo de altitude, a sort of remnant of Atlantic forest in the semiarid region with predomination of the xeromorphic Brazilian caatinga. This species was found in Areia, a small municipality in the state of Paraíba, northeastern Brazil. The chaetotaxy scheme follows the system of Christiansen \& Bellinger (2000) modified from Jacquemart (1974).

\section{MATERIALAND METHODS}

The specimens were collected during the dry season with entomological aspirators, directly from litter and soil samples transferred to white trays. The specimens were fixed in ethanol at $70 \%$.

The specimens were mounted on glass slides with Hoyer liquid following the procedures described by Christiansen \& 
Bellinger (1998). The type material is deposited at the Museu Nacional, Universidade Federal do Rio de Janeiro (CM/MNRJ/ UFRJ).

The key to the species of Seira from Paraíba was made with the most common characters used in descriptions of species of Entomobryidae, like color patterns, dorsal chaetotaxy features, shape of antennae and feet complexes (Bellinger $e t$ al. 1996-2008; Christiansen \& Bellinger 2000).

The list with 21 species of Seira recorded in Brazil was obtained by the revision of Culik \& Zeppelini (2003), Zeppelini \& Bellini (2006) and Bellini \& Zeppelini (2005, 2008).

\section{Seira paraibensis sp. nov.}

(Figs. 1-3)

Etymology. The species was named after its type location.

Description. Total length of the holotype 2,05 mm, other measures are listed in Table I. Habitus typically entomobryid (Figs. 1, 2A). Color of specimens in alcohol pale yellow with light blue pigment covering the antennae and legs and dark blue pigment covering eyepatches, lateral borders of mesothorax and lateral borders of abdominal segments III and IV and distal femurs (Fig. 1). Color of specimens mounted in Hoyer, pale white, with light blue pigment covering antennal segments I and II, posterior half of the head, lateral borders of mesothorax and lateral borders of abdominal segments III and IV and legs. Dark blue pigment covering antennal segments III and IV, eye patches and anterior half of the head. Brownish rounded scales covering all antennal segments, head, thorax, abdomen, coxae, trochanters, femurs, tibiotarsi, manubrium and dens. Antennal segment IV weakly annulated, with a bilobed apical bulb and no pin setae (Fig. 2B). Eye patches

Table I. Comparative lengths of segments of the body of S. paraibensis sp nov. Ant. = Antennal Segment; Abd. = Abdominal Segment; C. D. = Cephalic Diagonal Measurements were taken from holotype.* conversion rate to $\mu \mathrm{m}=\mathrm{x} 10$

\begin{tabular}{lc}
\hline Segments & S. paraibensis \\
\hline Ant. IV & 64 \\
Ant. III & 36 \\
Ant. II & 31 \\
Ant. I & 20 \\
Head length & 35 \\
Head (C. D.) & 37 \\
Mesothorax & 27 \\
Metathorax & 16 \\
Abd. I & 11 \\
Abd. II & 12 \\
Abd. III & 16 \\
Abd. IV & 60 \\
Abd. V & 15 \\
Abd. VI & 6 \\
Manubrium & 40 \\
Dens & 54 \\
Mucro & 2 \\
\hline
\end{tabular}

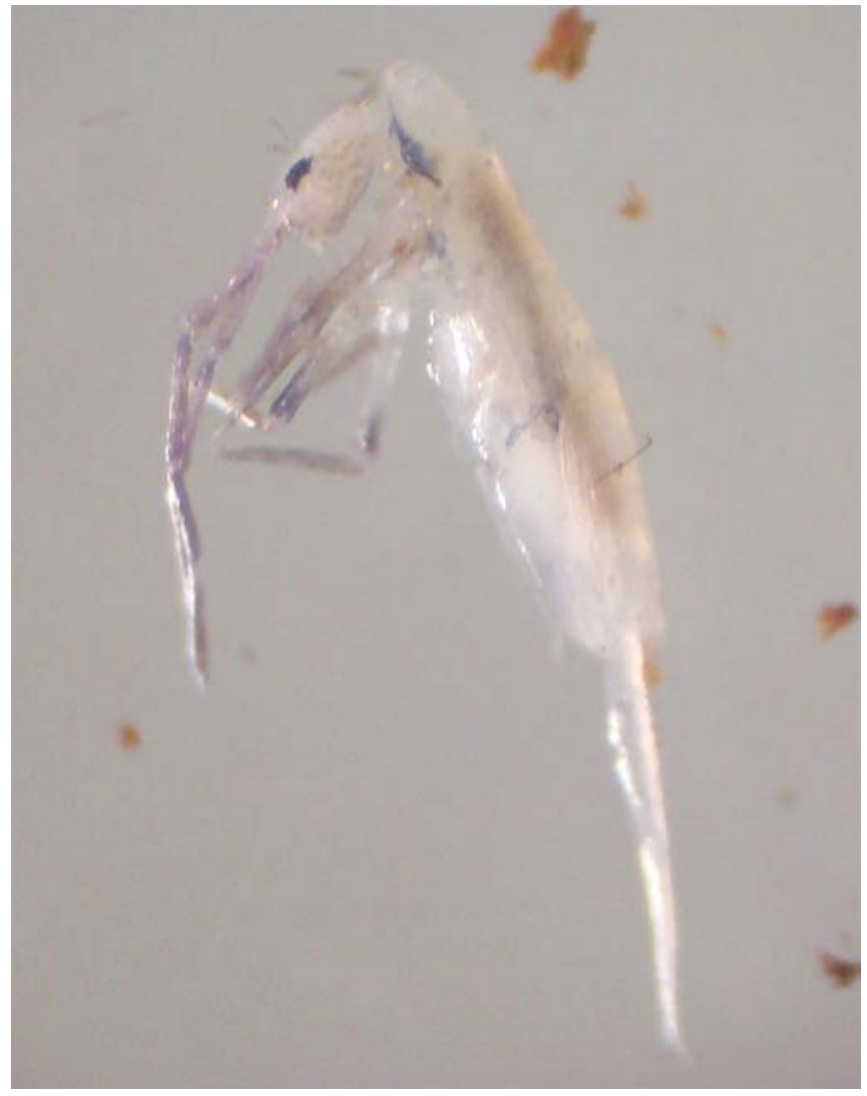

Fig. 1. S. paraibensis sp. nov. Habitus of a fixed specimen.

oval, with the largest lens being A and the smallest lens being G, with three interocular feathered setae (Fig. 2C). Pre-labral and labral setae smooth. Labial triangle seta $\mathrm{r}$ reduced, M1, M2 and E feathered (Fig. 2D). Trochanteral organ in V- shape with 32 spine-like setae (Fig. 2E). Pro, meso and meta ungues with four inner teeth, one pair at the basis and two unpaired teeth at the apex (Figs. 2F-H). Unguiculi truncate (Figs. 2F-H),

Table II. Comparison of characters of Seira species.

\begin{tabular}{lcccc}
\hline Species & $\begin{array}{c}\text { Lobes on } \\
\text { antennal } \\
\text { apical } \\
\text { bulb }\end{array}$ & $\begin{array}{c}\text { Annulations } \\
\text { on } 4^{\text {th }} \\
\text { antennal } \\
\text { segment }\end{array}$ & $\begin{array}{c}\text { Ratio } \\
\text { antenna / } \\
\text { cephalic } \\
\text { diagonal }\end{array}$ & $\begin{array}{c}\text { Unguiculus } \\
\text { shape }\end{array}$ \\
\hline paraibensis $^{*}$ & 2 & +- & 4.1 & TR \\
pseudoannulata $_{\text {annulata }}$ & 1 & + & 2.3 & TR \\
\hline
\end{tabular}

\begin{tabular}{lcccc}
\hline Species & $\begin{array}{c}\text { Number } \\
\text { of inner } \\
\text { ungual } \\
\text { teeth }\end{array}$ & $\begin{array}{c}\text { Distinctly } \\
\text { larger inner } \\
\text { ungual } \\
\text { tooth }\end{array}$ & $\begin{array}{c}\text { Spine-like } \\
\text { setae at } \\
\text { base of } \\
\text { dens }\end{array}$ & $\begin{array}{c}\text { Number of } \\
\text { ventral } \\
\text { manubrial } \\
\text { subapical setae }\end{array}$ \\
\hline paraibensis $^{*}$ & 4 & $\mathrm{M}+$, A- & - & 8 \\
pseudoannulata & 4 & - & - & 6 \\
annulata & 3 & - & - & $4 ?$ \\
\hline
\end{tabular}

$\mathrm{TR}=$ truncate; $\mathrm{A}-$ = minor apical; $\mathrm{M}+=$ larger medial + + = present $;$ - = absent; +- = present but weak; ? = uncertain. *Measurements were taken from the holotype. 

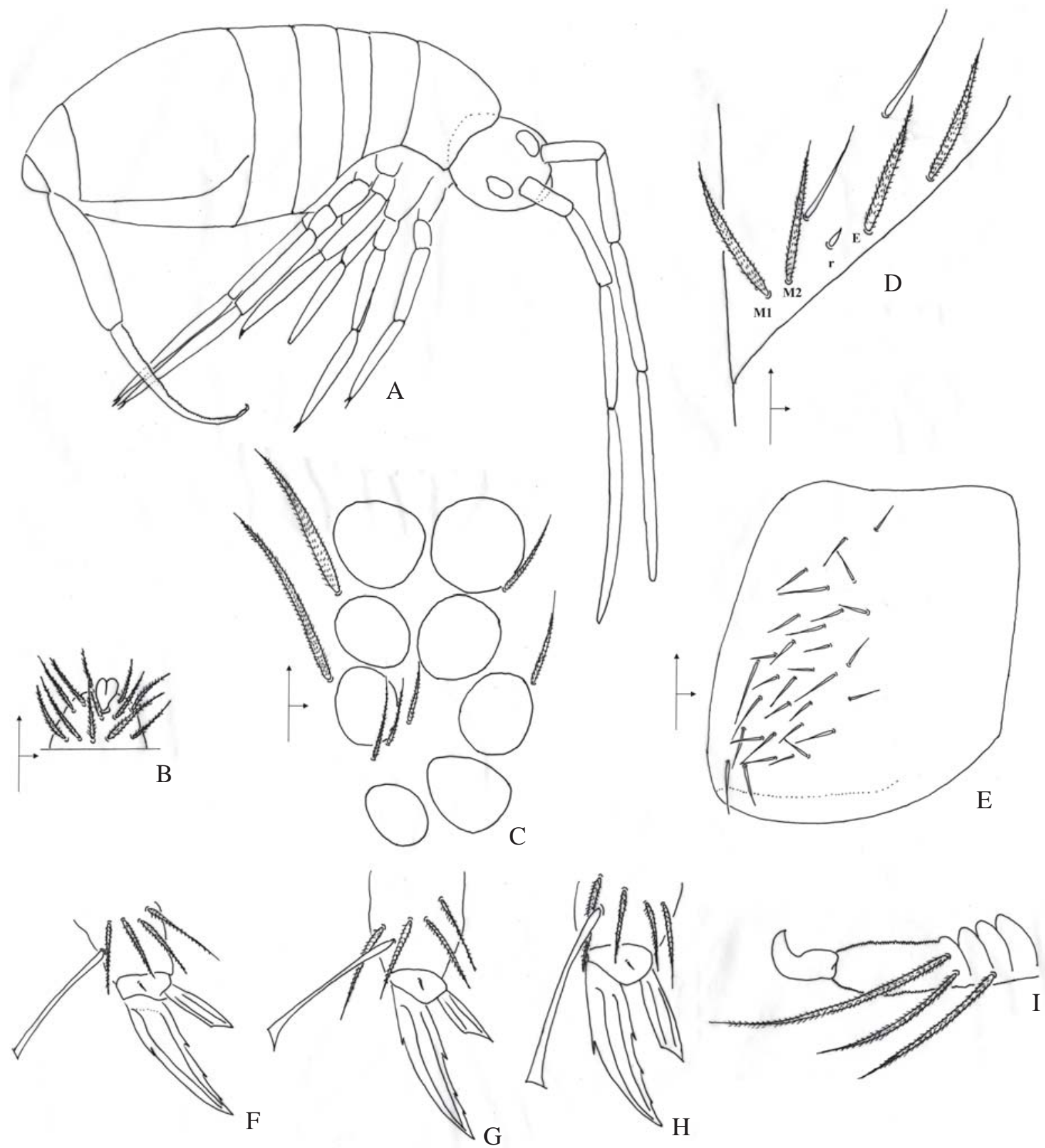

Fig. 2. S. paraibensis sp. nov. A, habitus; B, labial quaetotaxy; C, apical bulb of $4^{\text {th }}$ antennal segment; D, right eye patch; E, metatrochanteral organ; F, first foot complex; G, second foot complex; H, third foot complex; I, distal dens and mucro.

with slightly serrated edges. Tenent hair capitate (Figs. 2F-H) with smooth edges. Venter of manubrium with eight subapical setae. No spine-like setae present on the manubrium. Mucro typically falcated (Fig. 2I). Dorsal macrochaetae distribution of head and body as in fig. 3. Other characteristics are listed in Table II.

\section{Taxonomic Summary}

Holotype. BRAZIL, Paraíba: Areia, female, 11-XI-2008. Bellini \& Zeppelini leg. Paratypes. 4 males, 4 females. BRAZIL, Paraíba: Areia, 11/12-XI-2008. Bellini \& Zeppelini leg.
Habitat. The climate of the type locality is 'As' following Koeppen's system (Kottek et al. 2006) which means the main climate of the area is equatorial and the precipitation levels indicate a dry summer. Areia is located at 620 meters over the sea level and at approximately $93 \mathrm{~km}$ far away of the coast of Paraíba. The Good's biogeographic zone is 27 (Good 1974).

Remarks. The closest species to $S$. paraibensis sp. nov. is S. pseudoannulata Bellini \& Zeppelini, 2008. The cephalic regions 1,2 , and 4 have a similar number and pattern of distribution of macrochaetae. The cephalic region 5 has only 
one macrochaetae and there are no macrochaetae on cephalic region 6 on both species. On mesothorax, the superior half of region 2 and region $3 \mathrm{~A}$ have five macrochaetae each, in a similar distribution on the two species. Metathorax and abdominal segments I and II have the same dorsal chaetotaxy pattern, and the number of macrochaetae on region $\mathrm{B}$ of the abdominal segment III is the same in S. paraibensis sp. nov. and $S$. pseudoannulata. Both species also shares annulations on the antennae IV, truncate unguiculi, same teeth formulae on the claws, furthermore they are distributed in relatively adjacent areas, since the type locality of $S$. pseudoannulata is Mataraca, a municipality on the north coast of Paraíba State (Bellini \& Zeppelini 2008). Despite all these similarities both species can clearly be distinguished from each other by the presence of two macrochaetae on the cephalic region 3 of $S$. paraibensis sp. nov. and none on $S$. pseudoannulata, many differences on the dorsal chaetotaxy in fields $1,3 \mathrm{~B}, 3 \mathrm{C}$ of metathorax, the presence of one macrochaetae on region $\mathrm{A}$ of abdominal segment III in S. paraibensis sp. nov. and none in $S$. pseudoannulata, and a completely distinct chaetotaxy on abdominal segment IV on both species.

It's very likely that $S$. paraibensis sp. nov. and $S$. pseudoannulata are closely related. Another somewhat similar species is S. annulata (Handschin), 1927, which was also recorded in Brazil (Table III) (Culik \& Zeppelini 2003, Christiansen \& Bellinger 2000). The three species share annulations on antennae IV, truncate unguiculi, absence of macrochaetae on cephalic region 6 and they have similarities on the number and disposition of macrochaetae on regions 2 and $3 \mathrm{~A}$ of mesothorax, metathorax, and abdominal segments I, II and III (Christiansen \& Bellinger 2000, Bellini \& Zeppelini

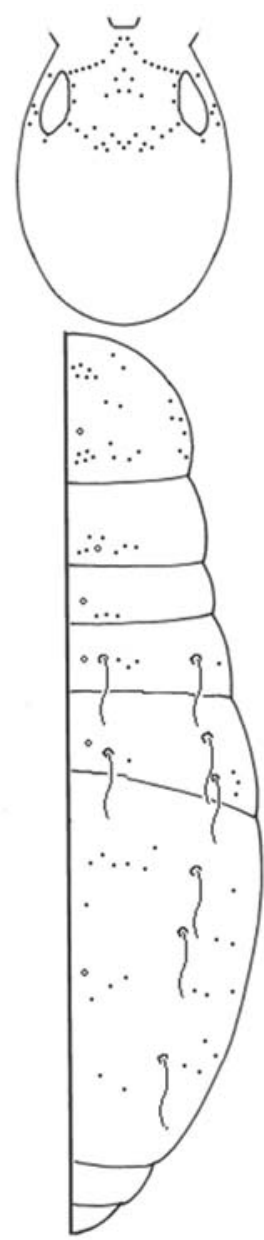

Fig. 3. S. paraibensis sp. nov. Dorsal macrochaetae distribution.

Table III. List of the Brazilian Seira species.

\begin{tabular}{|c|c|c|}
\hline Species & Brazilian distribution & Habitat \\
\hline S. annulata (Handschin, 1927) & SP & Close to a lagoon \\
\hline S. arenicola Bellini \& Zeppelini, 2008 & PB & Dune land, forest litter \\
\hline S. atrolutea (Arlé, 1939) & MS, SP & Unknown \\
\hline S. brasiliana (Arlé, 1939) & MS, PB, RJ, SP & Unknown \\
\hline S. eidmanni (Stach, 1935) & RJ, SP & Ant nests, tree barks \\
\hline S. mataraquensis Bellini \& Zeppelini, 2008 & PB & Forest litter \\
\hline S. melloi (Arlé, 1939) & ES, RJ & Lichen, moss \\
\hline S. mendoncea Bellini \& Zeppelini, 2008 & PB & Top soil, litter \\
\hline S. mirianae Arlé \& Guimarães, 1981 & $\mathrm{~PB}, \mathrm{RJ}$ & Dune land, forest litter \\
\hline S. musarum Ridley, 1890 & PE (F. de Noronha) & On plants \\
\hline S. nigrans (Arlé, 1959) & MT, PB & Scrubland, litter \\
\hline S. nunezae Christiansen and Bellinger, 2000 & MS, SP & Litter, top soil \\
\hline S. paraibensis sp. nov. & PB & Forest litter \\
\hline S.paranensis (Stach, 1935) & PR & Unknown \\
\hline S.prodiga (Arlé, 1959) & MT, PB, PE, RJ & Forest litter \\
\hline S. pseudoannulata Bellini \& Zeppelini, 2008 & $\mathrm{~PB}$ & Forest litter \\
\hline S. pulcher (Handschin, 1924) & $\mathrm{SC}$ & Unknown \\
\hline S. raptora Zeppelini \& Bellini, 2006 & PB & Top soil, litter \\
\hline S. reichenspergeri (Handschin, 1924) & SC & Unknown \\
\hline S. subannulata (Denis, 1933) & ES, RJ & Lichen, moss \\
\hline S. xinguensis (Arlé, 1959)* & MT, PB & Litter, top soil \\
\hline
\end{tabular}

* S. xinguensis was considered here a full species taxon and not a subspecies of S. prodiga 


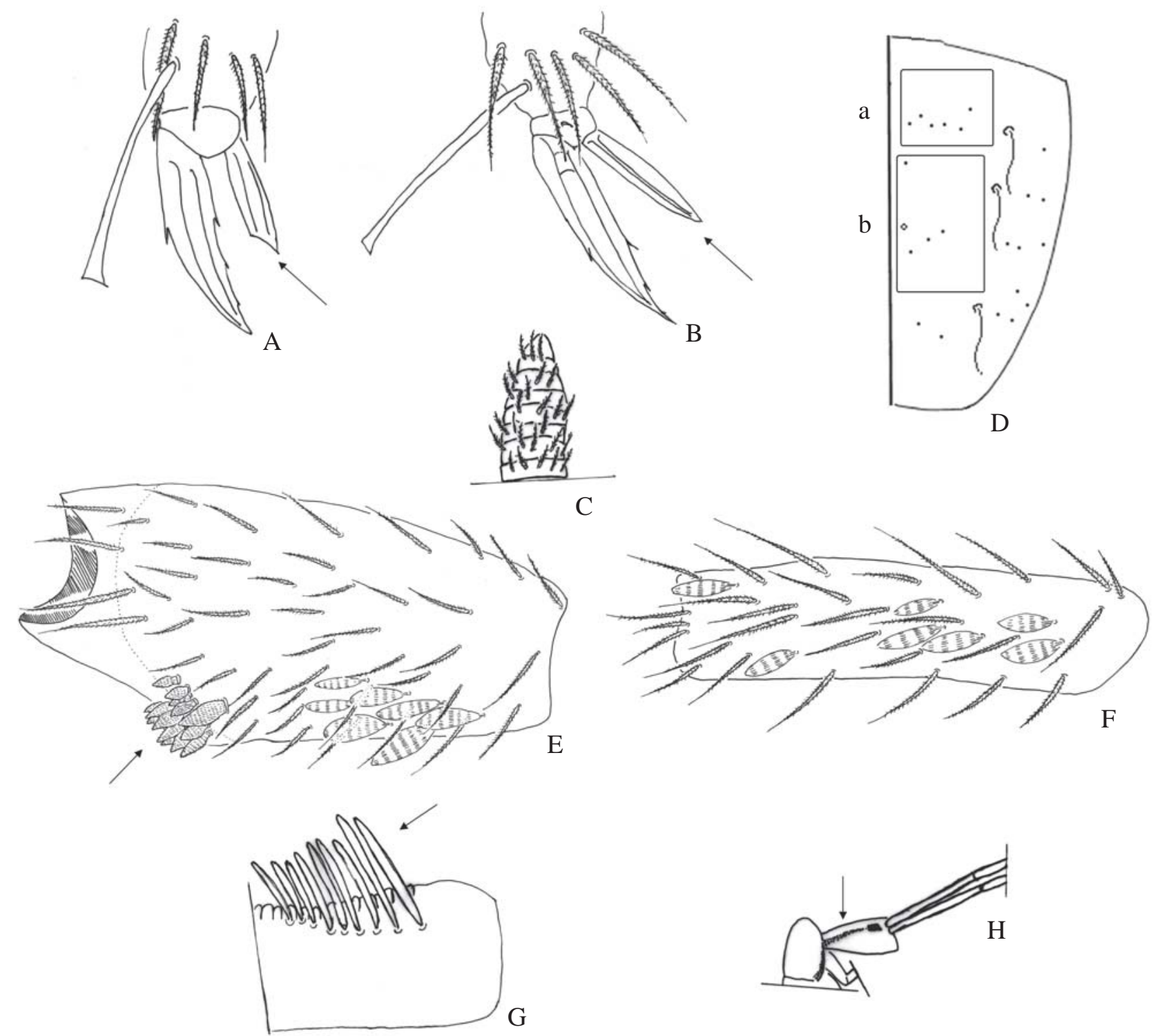

Fig. 4. A, Foot complex with a truncate unguiculus; B, foot complex with a acuminate unguiculus; C, apex of an annulate antenna; D, fourth abdominal segment showing regions a and b; E, enlarged femur with spines of males of S. raptora; F, regular femur of a Seira species; G, row of large blunt smooth setae on dens; $\mathrm{H}$, Head of S. xinguensis showing a dark lateral line of pigment.

2008). Other characters are listed on Table II. However, only a complete phylogenetic revision of the genus will clarify the real relationships among the species.

In Paraíba we found until present, including S. paraibensis sp. nov., 11 species of Seira (Bellini \& Zeppelini 2005, 2008; Zeppelini \& Bellini 2006), with six new species identified and described to the state. In Brazil there are now 21 described species of Seira, as shown in Table III.

A key to the species from Paraíba is presented below. $S$. prodiga Arlé, 1959, S. xinguensis Arlé, 1959 and S. nigrans Arlé, 1959 can only be distinguished from each other by distinct color patterns (Arlé 1959) and the ratio of some segments (Christiansen \& Bellinger 2000). It is possible that $S$. prodiga and $S$. xinguensis are the same species (Arlé 1959), and the dorsal chaetotaxy of $S$. nigrans was not presented in any literature. A revision of the three taxa is important to indicate the true status of them.

Key to the species of Seira from Paraíba, Brazil

1. Unguiculi truncate (Fig. 4A), fourth antennal segment annulate (Fig. 4C)

Unguiculi acuminate (Fig. 4B), fourth antennal segment not annulate ..................................................................... 3

2. Regions $\mathrm{a}$ and $\mathrm{b}$ of the fourth abdominal segment with $6+6$ and 4+4 macrochaetae respectively (Fig. 4D)

S. paraibensis sp. nov.

Region a of the fourth abdominal segment with $4+4$ macrochaetae and region $\mathrm{b}$ without macrochaetae ...... S. pseudoannulata 
3. First abdominal segment without macrochaetae First abdominal segment with at least $2+2$ macrochaetae .5

4. Metathorax with $10+10$ macrochaetae or more; femurs of the first pair of legs of males greatly enlarged, bearing spines in a ventral projection (Fig. 4E)

S. raptora

Metathorax with 6+6 macrochaetae; first pair of legs of males similar to the females (Fig. 4F) ........... S. mirianae

5. Dens with a row of large blunt smooth setae (Fig. 4G) ... 6 Dens normal, without large blunt setae ...8

6. Head dark S. nigrans

Head pale ... 7

7. Head with a dark lateral line of pigment starting behind the eye patches (Fig. $4 \mathrm{H}$ ) S. xinguensis

Head without a lateral line of pigment S. prodiga

8. First abdominal segment with $4+4$ or less macrochaetae .. 9 First abdominal segment with $5+5$ macrochaetae 10

9. First abdominal segment with $2+2$ macrochaetae; dorsal vertex of the head with $4+4$ macrochaetae .. S. brasiliana

First abdominal segment with 4+4 macrochaetae; dorsal vertex of the head without macrochaetae

S. mataraquensis

10. Regions a and $\mathrm{b}$ of the fourth abdominal segment with $2+2$ and 4+4 macrochaetae respectively S. mendoncea

Region a of the fourth abdominal segment with $2+2$ macrochaetae and region $\mathrm{b}$ without macrochaetae .......

S. arenicola

Acknowledgements. Support for this study was provided by a grant to the senior author by $\mathrm{CNPq} / \mathrm{MCT} / \mathrm{Brazil}$.

\section{REFERENCES}

Arlé, R. 1959. Collembola Arthropleona do Brasil oriental e central. Arquivos do Museu Nacional 49: 155-211.
Barra, J. A. 2004. Le genre Seira (Collembola, Entomobryidae) du Yémen continental. Zoosystema 26: 291-306.

Bellinger, P. F.; K. A. Christiansen \& F. Janssens. 1996-2008. Checklist of the Collembola of the World. Available from: <http:// www.collembola.org>. Last acessed on 11/11/2008.

Bellini, B. C. \& D. F. Zeppelini. 2005. First records of Collembola (Ellipura) from the state of Paraíba, Northeastern Brazil. Revista Brasileira de Entomologia 48: 587-588.

Bellini, B. C. \& D. Zeppelini. 2008. Three new species of Seira Lubbock (Collembola, Entomobryidae) from Mataraca, Paraíba State, Brazil. Zootaxa 1773: 44-54.

Christiansen, K. \& P. Bellinger. 1998. The Collembola of North America. North of Rio Grande. Grinnell College, Grinnell, Iowa. $1322 \mathrm{p}$.

Christiansen, K. \& P. Bellinger. 2000. A survey of the genus Seira (Collembola: Entomobryidae) in the Americas. Caribbean Journal of Science 36: 39-75.

Culik, M. \& D. F. Zeppelini. 2003. Diversity and distribution of Collembola (Arthropoda: Hexapoda) of Brazil. Biodiversity and Conservation 12: 1119-1143.

Good, R. 1974. The geography of flowering plants. Longman Group, United Kingdom, London (4 ${ }^{\text {th }}$ edition), $574 \mathrm{p}$.

Jacquemart, S. 1974. Résultats de la mission Anthropologique Belge au Niger. Collemboles nouveaux du Sahara. Bulletin de l'Institut Royal des Sciences Naturelles de Belgique 50: 1-46.

Kottek, M.; J. Grieser; C. Beck; B. Rudolf \& F. Rubel. 2006. World Map of the Köppen-Geiger climate classification updated. Meteorologische Zeitschrift 15: 259-263.

Mari Mutt, J. A. 1986. Puerto Rican species of Seira (Collembola: Entomobryidae). Caribbean Journal of Science 22: 145-158.

Mari Mutt, J. A. \& P. F. Bellinger. 1990. A catalog of the Neotropical Collembola. Flora \& Fauna Handbook No. 5. Sandhill Crane Press, Gainesville, Florida, 237 p.

Mari Mutt, J. A. \& P. F. Bellinger. 1996. Supplement to the Catalog of the Neotropical Collembola - August 1989 to April 1996. Caribbean Journal of Science 32: 166-175.

Mari Mutt, J. A; P. F. Bellinger \& F. Janssens. 1998-2008. Supplement to the Catalog of the Neotropical Collembola. Available from: http://www.collembola.org/publicat/neotrcat.htm>. Last acessed on $11 / 11 / 2008$.

Soto-Adames, F. N. 2008. Postembryonic development of the dorsal chaetotaxy in Seira dowlingi (Collembola, Entomobryidae); with an analysis of the diagnostic and phylogenetic significance of primary chaetotaxy in Seira. Zootaxa 1683: 1-31.

Soto-Adames, F. N.; J. A. Barra; K. Christiansen \& R. Jordana. 2008. Suprageneric Classification of Collembola Entomobryomorpha. Annals of the Entomological Society of America 101: 501513.

Zeppelini, D. F. \& B. C. Bellini. 2006. Two Seira Lubbock 1869 (Collembola, Arthropleona, Entomobryidae) new to science, with remarkable secondary sexual characters. Zootaxa 1185: 21-35. 